\title{
Qualidade de vida no trabalho: uma análise sobre a percepção dos colaboradores da cooperativa Camnpal
}

Quality of life at work: an analysis on the perception of collaborators of camnpal cooperative

\section{Resumo}

Este estudo teve o objetivo de identificar junto aos colaboradores da Cooperativa Camnpal, como avaliam sua Qualidade de Vida no Trabalho. É uma pesquisa aplicada, com abordagem quantitativa, quanto aos objetivos é exploratória, descritiva e uma pesquisa de campo. A coleta de dados ocorreu através de um questionário com 30 questões tendo em vista as oito categorias do modelo de Walton (1973). Os resultados mostraram que os funcionários estão satisfeitos em relação à relevância social da vida no trabalho, constitucionalismo, oportunidades de crescimento e segurança, Somente o uso e desenvolvimento das capacidades e as condições de trabalho, necessitam de melhorias.

Palavras-chave: qualidade de vida no trabalho. cooperativa agropecuária. camnpal. modelo Walton.

\begin{abstract}
This study aimed to identify with collaborators of Camnpal Cooperative, how they evaluate their Quality of Life at Work. It is an applied research, with quantitative approach, as the objectives is exploratory, descriptive and a field research. Data collection occurred through a questionnaire with 30 questions considering the eight categories of Walton's model (1973). The results showed that employees are satisfied with the social relevance of working life, constitutionalism, growth opportunities and security. Only the use and development of skills and working conditions need improvement.
\end{abstract}

Keywords: quality of life job. cooperativa agropecuária. CAMNPAL. Walton model.

Andressa Fernandes Gaier ' , Jaime Peixoto Stecca II , Denise Adriana Johann ${ }^{\text {III }}$, Nandria Scherer ${ }^{\mathrm{IV}}$, Ricardo Alberti ${ }^{\mathrm{V}}$

${ }^{\mathrm{I}}$ Universidade Federal de Santa Maria- UFSM, andressagayer@yahoo.com.br

${ }^{\text {II }}$ Universidade Federal de Santa Maria- UFSM, Jaime@ufsm.br

${ }^{\text {III }}$ Universidade Federal de Santa Maria- UFSM, johanndenisee@gmail.com

${ }^{\text {IV }}$ Universidade Federal de Santa Maria- UFSM, nandriaschererb@hotmail.com

${ }^{\mathrm{V}}$ Universidade Federal de Santa Maria- UFSM, r-alberti@live.com 


\section{Introdução}

A qualidade de Vida no Trabalho (QVT) surge com a inserção que favorece o desenvolvimento humano no ambiente de trabalho, pois se percebe que o fator humano é um dos principais recursos dentro da organização e serve como força vital para o alcance dos objetivos damesma. Para Souza et al. (2019) Os dias atuais trazem mudanças e incertezas ao meio organizacional, as cooperativas buscam competitividade e produtividade com qualidade, e seu sucesso está ligado a satisfação das pessoas que a compõem, visto que a qualidade de vida no trabalho afeta diretamente a motivação do colaborador e, portanto, o desempenho da cooperativa.

Desta forma, a Qualidade de Vida no Trabalho manifesta-se como um diferencial e uma estratégia de gestão nas organizações, buscando atender ás necessidades dos colaboradores e se preocupando com o bem estar e condições de trabalho oferecidas. Segundo Búrigo (1997, p. 30), a Qualidade de Vida no Trabalho "busca humanizar as relações de trabalho na organização, mantendo uma relação estreita com a produtividade e principalmente com a satisfação do trabalhador no seu ambiente de trabalho".

Com o passar do tempo outros autores buscaram elucidar definições da QVT, para Kops, Costa e Romero (2013) a QVT torna o ambiente de trabalho mais saudável, e como consequência, ter melhor qualidade e produtividade. Ferreira (2014) define a QVT como um conjunto de ações com caráter gerencial, tecnológico e estrutural implantadas na organização. As definições levam a perceber que a QVT está cada vez mais presente na vida das pessoas, pois as mesmas estão em busca de uma melhor expectativa de trabalho, este que lhe traga bem estar e satisfação.

Baseando-se nos pressupostos abordados e os que serão vistos no decorrer do estudo, é possível observar que a QVT é importante dentro da organização nos dias de hoje, pois para desenvolver as tarefas com qualidade por parte dos colaboradores é necessário ter pessoas satisfeitas e motivadas no seu ambiente de trabalho e para isso a responsabilidade principal é por parte da organização. Dessa forma este estudo busca identificar junto aos colaboradores da Cooperativa Camnpal como avaliam sua Qualidade de Vida no Trabalho.

\section{Referencial Teórico}

\subsection{Qualidade de vida no trabalho}

A origem do movimento de qualidade de vida no trabalho se deu em 1950, com o surgimento da abordagem sociotécnica, através dos resultados de vários estudos de um dos principais pesquisadores, Eric Trist no Instituto Tavistoch em Londres. Entretanto, a expressão "Qualidade de Vida no Trabalho" só foi introduzida, publicamente, no início de da década de 70, pelo professor Louis Davis, em Los Angeles. (FERNANDES, 1996).

Assim com a criação da QVT muitos autores realizaram pesquisas a fim de trazer conhecimento a nova teoria, assim como Búrigo (1997) e mais tarde Kops, Costa e Romero (2013), Ferreira (2014) e (ALVES, 2011). Em seu estudo Alves (2011) trás Ações e/ou programas de promoção da QVT e seus resultados, o quadro 1 abaixo apresenta alguns dos resultados. 
Quadro 1 - Ações e/ou programas de promoção da QVT e seus resultados

\begin{tabular}{|c|c|}
\hline Ações/Programas & $\begin{array}{ll}\text { Principais resultados observados } \\
\end{array}$ \\
\hline Antitabagismo & Aumento da autoestima, aumento do desempenho e disposição, prevenção de doenças. \\
\hline $\begin{array}{l}\text { Avaliação de } \\
\text { desempenho }\end{array}$ & $\begin{array}{l}\text { Aumento do desempenho do trabalhador, aumento da produtividade, aumento da satisfação } \\
\text { profissional. }\end{array}$ \\
\hline Benefícios & $\begin{array}{l}\text { Motivação, satisfação profissional, satisfação das necessidades pessoais, aumento da } \\
\text { produtividade. }\end{array}$ \\
\hline $\begin{array}{l}\text { Controle de álcool e } \\
\text { drogas }\end{array}$ & $\begin{array}{l}\text { Redução de riscos, melhora na segurança operacional e da saúde dos trabalhadores, melhora } \\
\text { na autoestima, diminuição dos acidentes de trabalho e absenteísmo. }\end{array}$ \\
\hline Ergonomia & Aumento do desempenho nas atividades, redução dos acidentes de trabalho. \\
\hline $\begin{array}{l}\text { Estudo de cargos e } \\
\text { salários }\end{array}$ & $\begin{array}{l}\text { Mantêm seus recursos humanos, aperfeiçoamento da administração dos recursos humanos, } \\
\text { aumento da motivação e satisfação dos trabalhadores, aumento da produtividade }\end{array}$ \\
\hline Exercícios físicos & $\begin{array}{l}\text { Aumenta a disposição e satisfação dos trabalhadores, aumenta a tolerância ao estresse, } \\
\text { redução do absenteísmo, melhora do relacionamento interpessoal, redução dos acidentes de } \\
\text { trabalho, redução dos gastos médicos. }\end{array}$ \\
\hline Ginástica Laboral & $\begin{array}{l}\text { Prevenção e reabilitação de doenças ocupacionais, prevenção de acidentes de trabalho, } \\
\text { melhor integração entre os trabalhadores, diminuição do absenteísmo, aumento da } \\
\text { produtividade. }\end{array}$ \\
\hline $\begin{array}{l}\text { Higiene e segurança do } \\
\text { trabalho }\end{array}$ & $\begin{array}{l}\text { Gera um ambiente mais saudável, prevenção de riscos à saúde, diminuição dos acidentes de } \\
\text { trabalho, diminuição do absenteísmo e rotatividade, aumento da produtividade }\end{array}$ \\
\hline Musicoterapia & $\begin{array}{l}\text { Aumento da autoestima, aumento do desempenho profissional, melhora no relacionamento } \\
\text { interpessoal, aumento da tolerância ao estresse, prevenção de doenças. }\end{array}$ \\
\hline $\begin{array}{l}\text { Orientações } \\
\text { nutricionais }\end{array}$ & $\begin{array}{l}\text { Diminuição da obesidade, mudança no comportamento de risco, aumento do desempenho e } \\
\text { disposição, aumento da produtividade. }\end{array}$ \\
\hline $\begin{array}{c}\text { Preparação para } \\
\text { aposentadoria }\end{array}$ & $\begin{array}{l}\text { Motivação, satisfação profissional, aumento da autoestima, melhora na relação interpessoal, } \\
\text { descobrimento de novas habilidades e competências, benefícios na vida social e familiar do } \\
\text { trabalhador. }\end{array}$ \\
\hline Terapias alternativas & $\begin{array}{l}\text { Aumento da tolerância ao estresse, melhora no relacionamento interpessoal, aumento da } \\
\text { produtividade. }\end{array}$ \\
\hline $\begin{array}{l}\text { Treinamento e } \\
\text { desenvolvimento }\end{array}$ & $\begin{array}{l}\text { Aumento do capital intelectual, aperfeiçoamento das atividades, satisfação profissional, } \\
\text { aumento da produtividade. }\end{array}$ \\
\hline
\end{tabular}

Fonte: Alves (2011, p. 67) e Souza et al. (2019).

Tendo em vista que grande parte da vida dos colaboradores é dedicada ao trabalho e muitas vezes interferindo na vida pessoal, é necessário que a organização melhore a estrutura de seu ambiente de trabalho e proporcione aos colaboradores condições adequadas para que estes possam exercer suas tarefas e atividades com conforto e segurança visando melhorias, buscando melhores resultados organizacionais e investindo em programas de QVT.

Dessa forma é possível verificar que vários elementos como a motivação e o estresse giram em torno da QVT e é possível obter benefícios através dela como o aumento da produtividade e a prevenção de riscos à saúde. Dessa forma aconselha-se que cooperativas invistam em Programas de QVT, buscando proporcionar satisfação e motivação para os colaboradores (ALVES, 2011). O modelo de Walton é uma das principais ferramentas utilizadas para avaliar a QVT em um ambiente de trabalho, por se considerar completa e apresentar diversas características visíveis no dia a dia.

\subsection{Modelo de qualidade de vida no trabalho de Walton (1973)}

Segundo França (2004, p. 34), o trabalho de Walton (1973) forneceu um modelo de analise de experimentos importantes sobre Qualidade de Vida no Trabalho com oito categorias conceituais como critérios de QVT, incluindo: Compensação justa e adequada, condições de trabalho seguras e saudáveis, oportunidades imediatas para desenvolver e usar as capacidades humanas, oportunidades futuras para o crescimento contínuo e a garantia de emprego, integração social na organização, constitucionalismo na organização, trabalho e espaço total na vida do indivíduo, e relevância social do trabalho. 
Embora não sejam desconhecidas a diversidade das preferencias e as diferenças individuais relativas à cultura, classe social, educação, formação e personalidade, tais fatores são intervenientes, de modo geral, na Qualidade de Vida do Trabalho.

\subsection{Categorias do modelo de Walton para QVT}

Segundo Walton (1973), as categorias que suprem uma estrutura para análise das características evidentes da QVT são: compensação justa e adequada, condições de trabalho, uso e desenvolvimento de capacidades, oportunidade de crescimento e segurança, integração social na organização, constitucionalismo, trabalho e espaço total de vida e relevância social da vida no trabalho. Walton associou oito dimensões para avaliação da QVT, conforme figura a seguir:

Quadro 2: Indicadores da Qualidade de vida no trabalho

\begin{tabular}{|c|c|}
\hline $\begin{array}{l}\text { Compensação } \\
\text { Justa e } \\
\text { Adequada }\end{array}$ & $\begin{array}{l}\text { Remuneração adequada: remuneração necessária para o empregado viver dignamente na sociedade } \\
\text { em que vive; } \\
\text { Eqüidade interna: eqüidade na remuneração entre membros da mesma organização; } \\
\text { Eqüidade externa: eqüidade na remuneração em relação a outros profissionais no mercado de } \\
\text { trabalho. }\end{array}$ \\
\hline $\begin{array}{c}\text { Condições de } \\
\text { Trabalho }\end{array}$ & $\begin{array}{l}\text { Jornada de trabalho: número de horas trabalhadas, e sua relação com as tarefas desempenhadas; } \\
\text { Carga de trabalho: quantidade de trabalho executados em um turno de trabalho; } \\
\text { Ambiente físico: local de trabalho e suas condições de bem-estar e organização para o desempenho } \\
\text { do trabalho; } \\
\text { Material e equipamentos: quantidade e qualidade de material disponível para a execução do } \\
\text { trabalho; } \\
\text { Ambiente Saudável: local de trabalho e suas condições de segurança e de saúde em relação aos riscos } \\
\text { de injúria ou de doenças; } \\
\text { Estresse: quantidade percebida de estresse a que o profissional é submetido em seu trabalho. }\end{array}$ \\
\hline $\begin{array}{l}\text { Uso e } \\
\text { Desenvolvimen } \\
\text { to de } \\
\text { Capacidades }\end{array}$ & $\begin{array}{l}\text { Autonomia: medida permitida, ao indivíduo, de liberdade na programação e execução de seu } \\
\text { trabalho; } \\
\text { Significado da tarefa: relevância da tarefa desempenhada na vida e no trabalho de outras pessoas; } \\
\text { Identidade da tarefa: medida da tarefa na sua integridade e na avaliação do resultado; } \\
\text { Variedade da habilidade: posssibilidade de utilização de uma larga escala de capacidades e de } \\
\text { habilidades do indivíduo; } \\
\text { Retroinformação: informação ao indivíduo acerca da avaliação do seu trabalho como um todo, e de } \\
\text { suas ações. }\end{array}$ \\
\hline $\begin{array}{l}\text { Oportunidade } \\
\text { de Crescimento } \\
\text { e Segurança } \\
\end{array}$ & $\begin{array}{l}\text { Possibilidade de carreira: viabilidade de oportunizar avanços na instituição e na carreira; } \\
\text { Crescimento pessoal: processo de educação continuada das potencialidades; } \\
\text { Segurança de emprego: grau de segurança quanto à manutenção do emprego. }\end{array}$ \\
\hline $\begin{array}{l}\text { Integração } \\
\text { Social na } \\
\text { Organização }\end{array}$ & $\begin{array}{l}\text { Igualdade de oportunidades: grau de ausência de estratificação na organização de trabalho; } \\
\text { Relacionamento: grau de realcionamento marcado por auxílio recíproco, apoio sócio-emocional, } \\
\text { abertura interpessoal e respeito às individualidades; } \\
\text { Senso comunitário: grau de senso de comunidade existente na instituição. }\end{array}$ \\
\hline $\begin{array}{c}\text { Constitucionali } \\
\text { smo }\end{array}$ & $\begin{array}{l}\text { Direitos trabalhistas: cumprimento dos direitos do trabalhador; } \\
\text { Privacidade pessoal: grau de privacidade que o empregado possui dentro da instituição; } \\
\text { Liberdade de expressão: forma como o empregado pode expressar seus pontos de vista aos } \\
\text { superiores; } \\
\text { Normas e rotinas: maneira como normas e rotinas influenciam o desenvolvimento do trabalho. }\end{array}$ \\
\hline $\begin{array}{l}\text { Trabalho e } \\
\text { Espaço Total de } \\
\text { Vida }\end{array}$ & $\begin{array}{l}\text { Papel balanceado no trabalho: equilíbrio entre jornada de trabalho, exigências de carreiras, viagens, } \\
\text { e convívio familiar; } \\
\text { Horário de entrada e saída do trabalho: equilíbrio entre horários de entrada e saída do trabalho e } \\
\text { convívio familiar. }\end{array}$ \\
\hline $\begin{array}{l}\text { Relevância } \\
\text { Social da Vida } \\
\text { no Trabalho }\end{array}$ & $\begin{array}{l}\text { Imagem da instituição: visão do empregado em reação à sua instituição de trabalho; } \\
\text { Responsabilidade social da instituição: percepção do empregado quanto à responsabilidade social da } \\
\text { instituição para a comunidade; } \\
\text { Responsabilidade social pelos serviços: percepção do empregado quanto à responsabilidade da } \\
\text { instituição para com a qualidade dos serviços postos à disposição da comunidade; } \\
\text { Responsabilidade social pelos empregados: percepção do empregado quanto à sua valorização e } \\
\text { participação na instituição, a partir da políitica de Recursos Humanos. }\end{array}$ \\
\hline
\end{tabular}

Fonte: Walton (1973). 
O modelo de QVT que enfatiza o trabalho como um todo, não se limitando a abordar somente o ambiente laboral em si, fazendo menção, inclusive, a aspectos presentes na vida de não trabalho. Trata-se, segundo o autor, de um conceito estreitamente relacionado à satisfação dos colaboradores quanto à sua capacidade produtiva em um ambiente de trabalho seguro, de respeito mútuo, com oportunidades de aprendizagem e com condições adequadas para o desempenho de suas funções. (LIOBA, 2014).

\section{Metodologia}

O presente estudo é uma pesquisa exploratória, descritiva e também é uma pesquisa de campo, exploratória, pois Segundo Gil (2012,) tem como principal finalidade desenvolver, esclarecer e modificar conceitos e ideias, tendo em vista a formulação de problemas mais precisos ou hipóteses pesquisáveis para estudos posteriores. E de campo por que "está voltada para o estudo de indivíduos, grupos, comunidades, instituições e outros campos, visando à compreensão de vários aspectos da sociedade" (MARCONI e LAKATOS, 2010, p. 172).

A abordagem utilizada é qualitativa e quantitativa, onde, a pesquisa qualitativa é a modalidade de pesquisa na qual os dados são coletados através de interações sociais e analisados subjetivamente pelo pesquisador (Rodrigues, 2007, p. 39). A pesquisa quantitativa se centra na objetividade, recolhidos como auxílio de instrumentos padronizados e neutros onde não se preocupa com representatividade numérica (GIL, 2012).

Os dados foram coletados junto a Cooperativa Camnpal através de um questionário elaborado pelos autores e aplicado aos colaboradores, baseado nas oito categorias do modelo de Walton (1973). O questionário foi elaborado em duas partes, onde a primeira foi apresentado o perfil do colaborador. A segunda era composta de 30 questões objetivas, separadas pelas categorias do modelo de Walton (1973). Os questionários foram aplicados no período de 11 de setembro de 2018, dos 71 colaboradores da organização usada como base de estudo, 48 responderam. Os dados foram analisados através de estatística simples no software Excel.

Esta pesquisa foi desenvolvida no supermercado da Cooperativa Camnpal de Nova PalmaRS. A cooperativa Camnpal, visa como negócio, fortalecer a empresa e o associado por meio do agronegócio. Tem como missão, buscar o desenvolvimento profissional dos associados e colaboradores, a geração de renda para todas as partes envolvidas, tendo como foco a qualidade dos produtos e serviços, respeitando o meio ambiente. A visão da Camnpal é aumentar em 8o\% a produção industrial, ser uma empresa consolidada financeiramente, aberta às transformações, respondendo às necessidades do quadro social, com as suas marcas em evidência na mente do consumidor. E por fim preza por valores como: cooperação, transparência, credibilidade, ética, respeito, responsabilidade ambiental, austeridade ponderada e criatividade. Completam a "família CAMNPAL" mais de 430 colaboradores, nos mais diversos setores e negócios. (CAMNPAL, 2018) 4 Declaração de Direito Autoral. 


\section{Análise dos resultados}

\subsection{Análise de Perfil}

Na sequência serão apresentados os dados de perfil dos colaboradores participantes da pesquisa.

Tabela 1 - Gênero

\begin{tabular}{c|c|c}
\hline Gênero & No colaboradores & Porcentual \\
\hline Feminino & 29 & $60 \%$ \\
\hline Masculino & 19 & $40 \%$ \\
\hline Total & 48 & $100 \%$ \\
\hline
\end{tabular}

Fonte: Dados da Pesquisa

Conforme a Tabela 1 pode-se observar no Supermercado Camnpal que há predominância de $60 \%$ do gênero feminino e $40 \%$ são do gênero masculino, percebe-se com isso que as mulheres são a maioria entre os entrevistados devido aos cargos oferecidos pela organização, que geralmente são ocupados por mulheres.

Tabela 2 - Faixa etária dos colaboradores

\begin{tabular}{c|c|c}
\hline Faixa Etária & No colaboradores & Porcentual \\
\hline Até 20 anos & 8 & $17 \%$ \\
\hline 21 a 30 anos & 18 & $38 \%$ \\
\hline 31 a 40 anos & 12 & $25 \%$ \\
\hline 41 a 50 anos & 8 & $17 \%$ \\
\hline $\begin{array}{c}\text { Acima de 51 } \\
\text { anos }\end{array}$ & 2 & $4 \%$ \\
\hline Total & 48 & $100 \%$ \\
\hline
\end{tabular}

Fonte: Dados da Pesquisa

Em relação à faixa etária evidencia-se que $38 \%$ dos entrevistados tem idade entre 21 a 30 anos, $17 \%$ deles tem idade até 20 anos, $25 \%$ entre 31 a 40 anos, $17 \%$ tem de 41 a 50 anos e somente $4 \%$ são acima de 51 anos.

Tabela 3 - Estado civil dos colaboradores

\begin{tabular}{c|c|c}
\hline Estado civil & No colaboradores & Porcentual \\
\hline Casado (a) & 20 & $42 \%$ \\
\hline Solteiro (a) & 20 & $42 \%$ \\
\hline União estável & 7 & $15 \%$ \\
\hline Viúvo (a) & 0 & $0 \%$ \\
\hline $\begin{array}{c}\text { Separado (a) } \\
\text { desquitado (a) }\end{array}$ & 1 & $\mathbf{2} \%$ \\
\hline $\begin{array}{c}\text { Não quero } \\
\text { declarar }\end{array}$ & 0 & $0 \%$ \\
\hline Outro & 0 & $0 \%$ \\
\hline Total & 48 & $100 \%$ \\
\hline
\end{tabular}

Fonte: Dados da Pesquisa

Quanto ao estado civil dos mesmos pode-se observar que $42 \%$ são casados e $42 \%$ solteiros, seguindo de $15 \%$ com união estável e $4 \%$ separados/desquitados. 
Tabela 4 - Grau de escolaridade

\begin{tabular}{l|c|c}
\hline \multicolumn{1}{c|}{ Grau de escolaridade } & № colaboradores & Porcentual \\
\hline Ensino Fundamental & 8 & $17 \%$ \\
\hline Ensino Médio/Técnico & 23 & $48 \%$ \\
\hline Ensino Superior Incompleto & 3 & $6 \%$ \\
\hline Ensino Superior Completo & 13 & $27 \%$ \\
\hline Especialização & 1 & $2 \%$ \\
\hline Total & 48 & $100 \%$ \\
\hline
\end{tabular}

Fonte: Dados da Pesquisa

Sobre o grau de escolaridade, foi possível observar um número maior de colaboradores que concluíram seus estudos até o ensino médio/técnico com $48 \%$, seguindo de $27 \%$ dos entrevistados que apresenta ensino superior completo, $6 \%$ ainda não concluíram o ensino superior, $17 \%$ estudaram até o ensino fundamental e somente $2 \%$ deles tem alguma especialização.

\subsection{Análises das categorias de QVT de Walton}

O modelo de Walton (1973) aborda oito categorias para medir a QVT, que são: compensação justa e adequada, condições de trabalho, uso e desenvolvimento das capacidades, oportunidade de crescimento e segurança, integração social na organização, constitucionalismo, trabalho e espaço total da vida e relevância social da vida no trabalho.

\subsubsection{Categoria 1 - Compensação Justa e Adequada}

A compensação justa e adequada visa mensurar a qualidade de vida no trabalho em relação à remuneração e salário adequado ao trabalhador, benefícios oferecidos pela organização, equidade interna e externa. A Tabela a seguir ilustra os resultados das questões aplicadas através do questionário aos colaboradores do supermercado Camnpal sobre esta categoria, onde foram desenvolvidas quatro questões com critérios que possam avaliar a satisfação dos mesmos referentes à remuneração, benefícios oferecidos e demais características. No quadro 3 será possível visualizar as respostas obtidas

Quadro 3 - Respostas Obtidas sobre Compensação Justa e Adequada

\begin{tabular}{|c|c|c|c|c|c|}
\hline \multicolumn{6}{|c|}{$\begin{array}{l}1 \text { - Você recebe alguma outra forma de remuneração na cooperativa como: auxílio alimentação, plano de saúde, } \\
\text { premiações ou outros benefícios ofertados pela organização? }\end{array}$} \\
\hline \begin{tabular}{c|c|} 
Não \\
Respondeu
\end{tabular} & $\begin{array}{c}\text { Discordo } \\
\text { Totalmente }\end{array}$ & $\begin{array}{c}\text { Discordo } \\
\text { Parcialmente }\end{array}$ & $\begin{array}{c}\text { Não } \\
\text { Concorda }\end{array}$ & $\begin{array}{c}\text { Concordo } \\
\text { Parcialmente }\end{array}$ & $\begin{array}{l}\text { Concordo } \\
\text { Totalmente }\end{array}$ \\
\hline $6 \%$ & $6 \%$ & $\mathbf{0} \%$ & $5 \%$ & $23 \%$ & $60 \%$ \\
\hline \multicolumn{6}{|c|}{2 - Sua renda mensal (salário e benéficos) lhe permite uma vida digna, suprindo as necessidades básicas? } \\
\hline $8 \%$ & $4 \%$ & $19 \%$ & $13 \%$ & $31 \%$ & $25 \%$ \\
\hline \multicolumn{6}{|c|}{$\begin{array}{l}\text { 3- O salário recebido por outras pessoas que ocupam o mesmo cargo na cooperativa é igual ao recebido por } \\
\text { você? }\end{array}$} \\
\hline $10 \%$ & $17 \%$ & $4 \%$ & $19 \%$ & $31 \%$ & $19 \%$ \\
\hline \multicolumn{6}{|c|}{$\begin{array}{l}4 \text { - O salário recebido por outras pessoas que ocupam o mesmo cargo em outras organizações é igual ao } \\
\text { recebido por você? }\end{array}$} \\
\hline $10 \%$ & $10 \%$ & $17 \%$ & $19 \%$ & $35 \%$ & $8 \%$ \\
\hline
\end{tabular}

Fonte: Dados da Pesquisa

Analisando a primeira questão em relação à compensação justa e adequada, o colaborador recebe alguma outra forma de remuneração na cooperativa como: auxilio alimentação, plano de saúde, premiações ou outros benefícios oferecidos pela organização, foram observados que $60 \%$ dos colaboradores concordam totalmente, $23 \%$ deles concordam parcialmente significando que ganham 
algumas das remunerações citadas, mas não estão inteiramente satisfeitos necessitando de modificações.

Ao perguntar se a renda mensal lhe permitia uma vida digna, suprindo as necessidades básicas notamos que houve resultados mais distribuídos conforme as opções oferecidas podem afirmar que $31 \%$ concordam parcialmente, $25 \%$ concordam totalmente, $19 \%$ discordam parcialmente, somente $4 \%$ discordam totalmente da afirmação e $8 \%$ não respondeu.

A Terceira questiona aos colaboradores se o salário recebido por outras pessoas que ocupam o mesmo cargo na cooperativa é igual ao recebido pelo mesmo, 31\% concordaram parcialmente, $19 \%$ concordaram totalmente, outros $19 \%$ não concordaram visto que $17 \%$ discordaram totalmente e somente $4 \%$ discordaram parcialmente, $10 \%$ deles não quiseram responder.

Por fim a quarta questão sobre equidade externa a pergunta realizada se o salário recebido por outras pessoas que ocupam o mesmo cargo em outras organizações é igual ao recebido pelo colaborador, percebemos que dos entrevistados 35\% concordaram parcialmente, 19\% não concordam, $17 \%$ discordam parcialmente, $10 \%$ discordam totalmente, e $10 \%$ não responderam.

A categoria compensação justa e adequada apresenta de modo geral um nível de satisfação mediano entre os entrevistados necessitando de algumas melhorias, levando em consideração os critérios avaliados, a questão 1 e 2 tratam da remuneração adequada para o colaborador, compreende que parte dos entrevistados avaliou de modo positivo, mas também houve avaliações negativas. Vem de encontro aos achados de Kops, Costa e Romero (2013).

Ainda na categoria de compensação justa e adequada foram realizadas as questões 3 e 4 com base nos dois critérios de equidade salarial interna e externa, onde se avalia um equilíbrio entre as remunerações na organização e a comparação da mesma com o mercado externo.

\subsubsection{Categoria 2 - Condições de Trabalho}

Esta categoria visa avaliar as condições de trabalho dos colaboradores com base em critérios que afetam a qualidade de vida no trabalho e fatores que possam ser prejudiciais à saúde e segurança dos mesmos. O quadro 4 evidencia as respostas obtidas.

O fator "condições de trabalho adequadas", como premissa de QVT, reforça algo bem conhecido na literatura científica no campo das ciências do trabalho: fornecer suporte organizacional aos trabalhadores é um dos requisitos fundamentais para o alcance dos objetivos prescritos. (FERREIRA, 2011, p.120).

Quadro 4 - Respostas Obtidas sobre Condições de Trabalho

\begin{tabular}{|c|c|c|c|c|c|}
\hline \multicolumn{6}{|c|}{ 5 - A carga horária é suficiente para desenvolver as atividades na cooperativa? } \\
\hline $\begin{array}{c}\text { Não } \\
\text { Respondeu }\end{array}$ & $\begin{array}{l}\text { Discordo } \\
\text { Totalmente }\end{array}$ & $\begin{array}{c}\text { Discordo } \\
\text { Parcialmente }\end{array}$ & $\begin{array}{c}\text { Não } \\
\text { Concorda }\end{array}$ & $\begin{array}{c}\text { Concordo } \\
\text { Parcialmente }\end{array}$ & $\begin{array}{l}\text { Concordo } \\
\text { Totalmente }\end{array}$ \\
\hline $4 \%$ & $3 \%$ & $\mathbf{8 \%}$ & $\mathbf{0} \%$ & $35 \%$ & $50 \%$ \\
\hline \multicolumn{6}{|c|}{6 - As atividades desenvolvidas afetam ou podem vir a afetar sua saúde física e mental? } \\
\hline $6 \%$ & $4 \%$ & $7 \%$ & $10 \%$ & $46 \%$ & $27 \%$ \\
\hline \multicolumn{6}{|c|}{$\begin{array}{c}7 \text { - As condições do ambiente de trabalho como: iluminação, ventilação, temperatura e higiene são adequadas } \\
\text { para desenvolver as atividades propostas? }\end{array}$} \\
\hline $4 \%$ & $\mathbf{2 \%}$ & $13 \%$ & $4 \%$ & $33 \%$ & $44 \%$ \\
\hline \multicolumn{6}{|c|}{$\begin{array}{c}8 \text { - Em relação a sua segurança no trabalho, a cooperativa disponibiliza equipamentos de proteção individual e } \\
\text { uma estrutura de trabalho segura? }\end{array}$} \\
\hline $6 \%$ & o\% & $\mathbf{2 \%}$ & $4 \%$ & $33 \%$ & $54 \%$ \\
\hline
\end{tabular}

Fonte: Dados da Pesquisa 
Ao perguntar ao colaborador se a carga horária era suficiente para desenvolver as atividades na cooperativa, foi possível perceber que $50 \%$ dos entrevistados concordam totalmente com a carga horária estipulada pela organização na realização das tarefas, 35\% concordam parcialmente, podemos considerar que a maior parte dos colaboradores acredita ser adequada a carga de trabalho designada pela cooperativa.

Quando se investiga se as atividades desenvolvidas afetam ou podem vir a afetar a saúde física e mental do colaborador é visível à insatisfação da maior parte dos entrevistados, pois $46 \%$ deles concordam parcialmente com a questão e $27 \%$ concordam totalmente, somando mais que a metade dos que discordam parcialmente ou totalmente com a situação. Observamos que os resultados foram negativos nesta questão, trazendo preocupação e alerta, é importante que a cooperativa se interesse mais com a saúde de seus colaboradores.

Ao analisar a questão sete, onde foi perguntado ao colaborador se as condições do ambiente de trabalho como: iluminação, ventilação, temperatura e higiene são adequadas para desenvolver as atividades propostas pela cooperativa, foi visto que $44 \%$ dos entrevistados avaliaram que concordam totalmente com as condições do ambiente de trabalho oferecidas pela organização, 33\% concordaram parcialmente necessitando de modificações.

Obteve-se um índice menor entre os colaboradores que não concordam e os que discordam parcialmente e totalmente, somando estes três níveis de avaliação foram percebidos que $19 \%$ deles estão insatisfeitos com o ambiente de trabalho para realizar suas tarefas, $4 \%$ não responderam.

A oitava questão aborda a segurança no trabalho, ao interpretar os resultados adquiridos percebe-se que mais que a metade dos entrevistados concorda totalmente com a segurança oferecida pela cooperativa totalizando $54 \%, 33 \%$ concorda parcialmente.

Para Martins (2011) as práticas relativas a condições físicas de trabalho, bem-estar, saúde e segurança devem ser inspiradas nas melhores práticas organizacionais, considerando os valores e expectativas dos empregados.

As questões referentes às condições de trabalho dos colaboradores da cooperativa Camnpal nela estão inseridas alguns critérios para medir a QVT, ao perceber os resultados como um todo é visível uma avaliação positiva, mas necessitando de alterações para melhorar ainda mais as condições oferecidas aos colaboradores.

As condições de trabalho podem ser avaliadas de vários pontos de vista, cujo um dos fatores mais importantes é a saúde física e mental do colaborador, vista na questão seis onde os resultados não foram satisfatórios, já que a maior parte dos colaboradores acredita que as atividades interferem na sua saúde, necessitando de mudanças por parte da organização.

\subsubsection{Categoria 3 - Uso e Desenvolvimento das Capacidades}

A terceira categoria visa à mensuração da QVT, onde o colaborador pode satisfazer suas necessidades de utilização das habilidades e de conhecimento, de desenvolver sua autonomia, autocontrole e de obter informações sobre o processo total do trabalho. (VIEIRA, 1996, p.45).

Usando uns dos critérios de avaliação de Walton (1973) que é o uso e desenvolvimento das capacidades, foi elaborado quatro questões sobre o assunto, com o intuito de avaliar como os colaboradores da cooperativa Camnpal percebem a categoria no dia a dia da organização. 
107 | Qualidade de vida no trabalho: uma análise...

Quadro 5 - Respostas Obtidas sobre Uso e Desenvolvimento de Capacidades

\begin{tabular}{|c|c|c|c|c|c|}
\hline \multicolumn{6}{|c|}{9 - Você se identifica com as funções exigidas pelo seu cargo e tem autonomia sobre ele? } \\
\hline \begin{tabular}{c|c} 
Não \\
Respondeu
\end{tabular} & $\begin{array}{c}\text { Discordo } \\
\text { Totalmente }\end{array}$ & $\begin{array}{c}\text { Discordo } \\
\text { Parcialmente }\end{array}$ & $\begin{array}{c}\text { Não } \\
\text { Concorda }\end{array}$ & $\begin{array}{l}\text { Concordo } \\
\text { Parcialmente }\end{array}$ & $\begin{array}{l}\text { Concordo } \\
\text { Totalmente }\end{array}$ \\
\hline $\mathbf{2} \%$ & $4 \%$ & $\mathbf{2 \%}$ & $4 \%$ & $38 \%$ & $50 \%$ \\
\hline \multicolumn{6}{|c|}{$\begin{array}{l}10 \text { - Quando se depara com um problema em suas tarefas, você tem autonomia para decidir a melhor } \\
\text { alternativa para soluciona-lo? }\end{array}$} \\
\hline $4 \%$ & $\mathbf{0} \%$ & $4 \%$ & $6 \%$ & $48 \%$ & $38 \%$ \\
\hline \multicolumn{6}{|c|}{11 - Em relação ao seu cargo e setor, você tem facilidade em participar das decisões propostas? } \\
\hline $4 \%$ & $\mathbf{0} \%$ & $\mathbf{2} \%$ & $6 \%$ & $44 \%$ & $44 \%$ \\
\hline \multicolumn{6}{|c|}{12 - Você tem oportunidade de aplicar todas as suas habilidades e capacidades nas funções realizadas? } \\
\hline $4 \%$ & $\mathbf{0} \%$ & $13 \%$ & $6 \%$ & $27 \%$ & $50 \%$ \\
\hline
\end{tabular}

Fonte: Dados da Pesquisa

A questão 9 está relacionada com a autonomia e identificação que o colaborador tem sobre seu cargo, ao ser perguntado se você se identifica com as funções exigidas pelo seu cargo e tem autonomia sobre ele, foi possível perceber que a metade dos entrevistados totalizando $50 \%$, concordaram totalmente com a situação e desses $38 \%$ concordaram parcialmente.

A questão 10 está relacionada ainda com a autonomia que o colaborador tem sobre suas tarefas e cargo, ao perguntar se quando se depara com um problema em suas tarefas, você tem autonomia para decidir a melhor alternativa para soluciona-lo, foi demonstrado que $38 \%$ concordam totalmente e $48 \%$ concordam parcialmente, $6 \%$ não concordam seguido de $4 \%$ que discordam parcialmente e $4 \%$ não quiseram responder.

Rodrigues (2007, p.89) afirma que "a autonomia reflete a responsabilidade e a capacidade do profissional planejar e decidir sobre seu trabalho". Analisando de modo geral as questões 9 e 10 no que se refere aos aspectos sobre autonomia e identificação com as funções, foi possível obter um resultado positivo.

A questão 11 investiga se o colaborador tem facilidade em participar das decisões propostas pela organização, evidencia-se positivamente em $88 \%$ dos colaboradores entrevistados, sendo que $44 \%$ concordaram totalmente e os outros $44 \%$ concordam parcialmente.

Ao questionar o colaborador se há oportunidade de aplicar todas as suas habilidades e capacidades nas funções realizadas, $50 \%$ concordam totalmente e $27 \%$ concordam parcialmente com a questão, para $19 \%$ dos entrevistados foi avaliado negativamente esta opinião, desses $6 \%$ não concordam e $13 \%$ discordam parcialmente somente $4 \%$ não responderam. Foi possível observar que os colaboradores tem a possibilidade de aplicar suas competências nas funções.

Com relação a está categoria, observamos um bom índice de satisfação por parte dos colaboradores, nas 4 questões aplicada. Percebe-se que a cooperativa oferece autonomia aos colaboradores para desenvolver suas atividades, isto é visto como fator positivo na organização por trazer motivação e entusiasmo ao colaborador.

A qualidade de vida no trabalho é maior quando a organização abre espaço para o colaborador contribuir com opiniões e sugestões, conforme visto na questão 11, a avaliação dos colaboradores foram positivas. Ao analisar a questão 12 é entendido que a cooperativa desfruta das habilidades e capacidades de seus colaboradores, pois eles conseguem aplicar todas elas no ambiente de trabalho.

\subsubsection{Categoria 4 - Oportunidade de crescimento e Segurança}

Esta categoria tem como finalidade medir a QVT em relação ás oportunidades que a organização oferece a seus colaboradores como desenvolvimento e crescimento pessoal dos mesmos. 
Quadro 6 - Respostas Obtidas sobre Oportunidade de crescimento e segurança

\begin{tabular}{|c|c|c|c|c|c|}
\hline \multicolumn{6}{|c|}{13 - A cooperativa possibilita avanços na carreira, dentro da organização? } \\
\hline \begin{tabular}{|c|} 
Não \\
Respondeu
\end{tabular} & $\begin{array}{c}\text { Discordo } \\
\text { Totalmente }\end{array}$ & $\begin{array}{c}\text { Discordo } \\
\text { Parcialmente }\end{array}$ & $\begin{array}{c}\text { Não } \\
\text { Concorda }\end{array}$ & $\begin{array}{c}\text { Concordo } \\
\text { Parcialmente }\end{array}$ & $\begin{array}{l}\text { Concordo } \\
\text { Totalmente }\end{array}$ \\
\hline $4 \%$ & $\mathbf{8 \%}$ & $\mathbf{8 \%}$ & $13 \%$ & $\mathbf{4 2} \%$ & $25 \%$ \\
\hline \multicolumn{6}{|c|}{14 - Os colaboradores buscam por aprendizado com o intuito de se manter e crescer dentro cooperativa? } \\
\hline 6\% & $\mathbf{0} \%$ & $6 \%$ & $\mathbf{8 \%}$ & $40 \%$ & $40 \%$ \\
\hline \multicolumn{6}{|c|}{$\begin{array}{l}15 \text { - A cooperativa incentiva o colaborador a crescer profissionalmente e pessoalmente, oferecendo treinament } \\
\text { cursos e desenvolvimento de suas competências? }\end{array}$} \\
\hline $4 \%$ & $\mathbf{2 \%}$ & $4 \%$ & $6 \%$ & $27 \%$ & $56 \%$ \\
\hline \multicolumn{6}{|c|}{$\begin{array}{l}16 \text { - Você acredita que exista segurança em relação à estabilidade no emprego desde que desenvolva suas tarefa } \\
\text { com competência? }\end{array}$} \\
\hline $8 \%$ & o\% & o\% & $2 \%$ & $29 \%$ & $60 \%$ \\
\hline
\end{tabular}

Fonte: Dados da Pesquisa

A questão 13 a ser analisada os avanços na carreira que o colaborador possa ter na organização, foi possível analisar que $67 \%$ dos colaboradores acreditam que existe está oportunidade, desses $42 \%$ concordaram parcialmente e $25 \%$ concordaram totalmente com a questão, obtendo um resultado positivo.

Foi questionado se os colaboradores buscam por aprendizado com o intuito de se manter e crescer dentro da cooperativa, foi percebido que $80 \%$ dos entrevistados concordam com a questão 14 , $40 \%$ concordaram totalmente e $40 \%$ concordaram parcialmente. Pode-se concluir que há interesse dos colaboradores em se manter na organização investindo em aprendizado para melhor desenvolver suas tarefas e futuramente avançar na carreira dentro da organização conforme resultados adquiridos na questão 14 .

Analisando a questão 15 é notório um resultado positivo em relação à pergunta realizada aos colaboradores onde foi questionado se a cooperativa incentiva o crescimento profissional e pessoal, oferecendo treinamento, cursos e desenvolvimento de suas competências, pôde-se ver que $56 \%$ dos entrevistados concordaram totalmente, $27 \%$ parcialmente.

Chiavenato (2014, p.311) afirma que a "informação guia o comportamento das pessoas e o torna mais eficaz e mais bem direcionado".

Conforme Robbins, Judge, Sobral (2010, p. 46), "quanto mais tempo uma pessoa fica em um emprego, menor a probabilidade de ela se demitir". Foi possível observar que a maioria dos entrevistados avalia de forma positiva está questão, $60 \%$ deles concordam totalmente, $29 \%$ concordam parcialmente.

Ao analisar as questões sobre a categoria 4, podemos destacar alguns pontos presentes na cooperativa e como os mesmos contribuem para a qualidade de vida dos colaboradores segundo Souza et al. (2019).

\subsubsection{Categoria 5- Integração Social na Organização}

Segundo Vieira (1996, p.45) a ausência de diferenças hierárquicas demasiadamente marcantes, apoio mútuo, fraqueza interpessoal e ausência de preconceito são pontos fundamentais para o estabelecimento de um bom nível de integração social nas empresas. Esta categoria trata diretamente a autoestima do colaborador no ambiente de trabalho. 
109 | Qualidade de vida no trabalho: uma análise...

Quadro 7 - Respostas Obtidas sobre Integração Social na Organização

\begin{tabular}{|c|c|c|c|c|c|}
\hline \begin{tabular}{|c|c} 
Não \\
Respondeu
\end{tabular} & $\begin{array}{c}\text { Discordo } \\
\text { Totalmente }\end{array}$ & $\begin{array}{c}\text { Discordo } \\
\text { Parcialmente }\end{array}$ & $\begin{array}{c}\text { Não } \\
\text { Concorda }\end{array}$ & $\begin{array}{l}\text { Concordo } \\
\text { Parcialmente }\end{array}$ & $\begin{array}{l}\text { Concordo } \\
\text { Totalmente }\end{array}$ \\
\hline \begin{tabular}{|l|}
$6 \%$ \\
\end{tabular} & $25 \%$ & $10 \%$ & $15 \%$ & $23 \%$ & $21 \%$ \\
\hline \multicolumn{6}{|c|}{18 - O relacionamento entre colegas e superiores é de respeito e cooperação? } \\
\hline \begin{tabular}{l|l}
$8 \%$ \\
\end{tabular} & $\mathbf{o} \%$ & $10 \%$ & $10 \%$ & $38 \%$ & $33 \%$ \\
\hline \multicolumn{6}{|c|}{$\begin{array}{c}19 \text { - Quando apresenta problemas e dificuldades no ambiente de trabalho é possível obter colaboração dos } \\
\text { colegas? }\end{array}$} \\
\hline \begin{tabular}{|l|l}
$8 \%$ \\
\end{tabular} & $4 \%$ & $2 \%$ & $\mathbf{0} \%$ & $50 \%$ & $35 \%$ \\
\hline
\end{tabular}

Fonte: Dados da Pesquisa

Ao falar em igualdade de oportunidades entre os indivíduos da organização foi possível analisar que a cooperativa apresenta dificuldades ao lidar com a igualdade entre todos dentro da cooperativa, pois mais da metade dos colaboradores não concorda com esta questão obtendo $15 \%$, logo $25 \%$ discordam totalmente, $10 \%$ discordam parcialmente e apenas $6 \%$ não responderam, os demais entrevistados acreditam que não a desigualdade entre os colaboradores tendo $21 \%$ que concordaram totalmente e $23 \%$ concordaram parcialmente.

A questão 18 aborda a importância do bom relacionamento e respeito entre os colegas e superiores. Para Ferreira (2011, p.127) o relacionamento social no contexto de trabalho é, principalmente, abordado como algo que é conveniente à saúde, ou seja, salutar, benéfico, proveitoso para quem trabalha em constantes e duradouros relacionamentos com outras pessoas. Neste quesito foi possível perceber um resultado positivo, pois $33 \%$ concordaram totalmente e $38 \%$ concordaram parcialmente com a questão totalizando mais de $71 \%$ dos entrevistados.

A última pergunta desta categoria traz o senso comunitário existente na organização, ao perguntar aos colaboradores se quando apresenta problemas e dificuldades no ambiente de trabalho é possível obter colaboração dos colegas, 35\% responderam que concordam totalmente e $50 \%$ concordam parcialmente com a situação.

A integração social na organização assume papel importante para os colaboradores, principalmente aos que estão sendo inseridos no ambiente de trabalho. Ao analisar a questão 17 obteve-se insatisfação por parte dos colaboradores ao serem perguntados se as oportunidades eram iguais para todos.

\subsubsection{Categoria 6- Constitucionalismo}

Esta categoria tem a finalidade de medir o grau em que os direitos dos colaboradores são cumpridos na organização, não só os direitos garantidos por lei, mas também a garantia de privacidade pessoal do colaborador, liberdade de expressar suas opiniões e também como as normas e rotinas da organização interferem o desenvolvimento de trabalho.

Quadro 8 - Respostas Obtidas sobre Constitucionalismo

\begin{tabular}{|c|c|c|c|c|c|}
\hline \multicolumn{6}{|c|}{$\begin{array}{c}20 \text { - A cooperativa cumpre com seus direitos trabalhistas e se houver algum erro tem liberdade para } \\
\text { questionar? }\end{array}$} \\
\hline \begin{tabular}{c|c|} 
Não \\
Respondeu
\end{tabular} & $\begin{array}{c}\text { Discordo } \\
\text { Totalmente }\end{array}$ & $\begin{array}{c}\text { Discordo } \\
\text { Parcialmente }\end{array}$ & $\begin{array}{l}\text { Não } \\
\text { Concorda }\end{array}$ & $\begin{array}{c}\text { Concordo } \\
\text { Parcialmente }\end{array}$ & $\begin{array}{l}\text { Concordo } \\
\text { Totalmente }\end{array}$ \\
\hline $4 \%$ & $\mathbf{2} \%$ & $\mathbf{o} \%$ & $4 \%$ & $31 \%$ & $58 \%$ \\
\hline \multicolumn{6}{|c|}{21 - Em relação a sua privacidade pessoal, a cooperativa e seus colegas respeitam seu direito de se reservar? } \\
\hline $4 \%$ & $\mathbf{2 \%}$ & $\mathbf{2 \%}$ & $6 \%$ & $27 \%$ & $58 \%$ \\
\hline \multicolumn{6}{|c|}{22 - Você consegue expressar seu ponto de vista aos superiores, sem ter medo de punições ou represálias? } \\
\hline \begin{tabular}{l|l}
$\mathbf{8} \%$ & \\
\end{tabular} & $\mathbf{2 \%}$ & $\mathbf{8 \%}$ & $10 \%$ & $44 \%$ & $\mathbf{2 7} \%$ \\
\hline \multicolumn{6}{|c|}{23 - As normas e rotinas exigidas pela cooperativa são compreensivas e realizadas por todos, sem } \\
\hline
\end{tabular}




\begin{tabular}{|c|c|c|c|c|c|}
\hline \multicolumn{5}{|c|}{ influenciar de modo negativo no ambiente de trabalho? } \\
\hline $\mathbf{8 \%}$ & $\mathbf{2 \%}$ & $\mathbf{4 \%}$ & $\mathbf{8 \%}$ & $\mathbf{4 6 \%}$ & $\mathbf{3 1 \%}$ \\
\hline
\end{tabular}

Fonte: Dados da Pesquisa

Abordando um dos critérios que compõe esta categoria, foi perguntado aos colaboradores se a cooperativa cumpre com seus direitos trabalhistas e se houver algum erro tem liberdade para questionar, foi possível perceber que a maior parte dos entrevistados concorda com a questão, pois $58 \%$ concordaram totalmente, $31 \%$ concordam parcialmente.

O colaborador tem direito de proteger sua privacidade, pois antes de exercer suas funções trabalhistas tem uma vida pessoal fora da organização. Em relação a sua privacidade pessoal a cooperativa e seus colegas respeitavam o direito de se reservar, $58 \%$ dos entrevistados responderam que concordam totalmente e $27 \%$ concordavam parcialmente.

Quando perguntado ao colaborador se o mesmo consegue expressar seu ponto de vista aos superiores, sem ter medo de punições e represálias, foi constatado que $44 \%$ concordaram parcialmente, $27 \%$ concordaram totalmente.

Schermerhorn, Hunt e Osborn (2007, p. 153-154) afirmam que os "gerentes, chefes de forçatarefa, chefes de comissões e líderes de equipe precisam todos ajudar seus grupos a adotar normas positivas que sejam um apoio aos objetivos da organização." Foi analisado que a maior parte deles concorda, pois $46 \%$ concordaram parcialmente, $31 \%$ concordaram totalmente obtendo um somatório de $78 \%$ positivamente.

Percebe-se que embora tenha algumas avaliações negativas, as positivas se sobrepõem. Através dos resultados percebeu que o cumprimento dos direitos trabalhistas e a privacidade pessoal dos colaboradores, são preservados pela cooperativa.

\subsubsection{Categoria 7- Trabalho e Espaço Total de Vida}

Está categoria foi desenvolvida para medir a QVT no ambiente de trabalho, visa equilibrar a vida pessoal e a profissional do colaborador, se importando se a jornada de trabalho não interfere na vida familiar e laser e também a representatividade que o trabalho tem na vida do trabalhador.

Quadro 9 - Respostas Obtidas sobre Trabalho e Espaço Total de Vida

\begin{tabular}{|c|c|c|c|c|c|}
\hline \multicolumn{6}{|c|}{24 - Devido a sua jornada de trabalho o tempo para lazer, atividades físicas e sociais são afetadas? } \\
\hline $\begin{array}{c}\text { Não } \\
\text { Respondeu }\end{array}$ & $\begin{array}{c}\text { Discordo } \\
\text { Totalmente }\end{array}$ & $\begin{array}{c}\text { Discordo } \\
\text { Parcialmente }\end{array}$ & $\begin{array}{c}\text { Não } \\
\text { Concorda }\end{array}$ & $\begin{array}{c}\text { Concordo } \\
\text { Parcialmente }\end{array}$ & $\begin{array}{l}\text { Concordo } \\
\text { Totalmente }\end{array}$ \\
\hline $4 \%$ & $\mathbf{2 \%}$ & $4 \%$ & $23 \%$ & $38 \%$ & $29 \%$ \\
\hline \multicolumn{6}{|c|}{25 - Existe facilidade em separar os problemas do trabalho da vida pessoal? } \\
\hline $4 \%$ & $4 \%$ & $6 \%$ & $13 \%$ & $31 \%$ & $42 \%$ \\
\hline \multicolumn{6}{|c|}{26 - A carga horária de trabalho exercida interfere no convívio familiar? } \\
\hline $10 \%$ & $8 \%$ & $4 \%$ & $15 \%$ & $35 \%$ & $27 \%$ \\
\hline
\end{tabular}

Fonte: Dados da Pesquisa

A questão 24 questiona os colaboradores se devido a sua jornada de trabalho o tempo de lazer, atividades físicas e sociais são afetadas, $38 \%$ concordaram parcialmente e $29 \%$ concordaram totalmente, observando que mais da metade dos colaboradores acreditam que a jornada de trabalho interfere para realizar as tarefas fora da organização, $23 \%$ não concordaram.

A questão 25 traz outro ponto importante na QVT, à dificuldade que os colaboradores possam ter em separar a vida pessoal dos problemas do trabalho, mais da metade tem facilidade em fazer está divisão, $42 \%$ concordaram totalmente, $31 \%$ concordaram parcialmente. 
111 | Qualidade de vida no trabalho: uma análise...

A última questão desta categoria analisa se a carga horária de trabalho exercida interfere no convívio familiar e foi possível observar que mais da metade estão satisfeito com a carga horária exercida na organização, $27 \%$ dos entrevistados concordaram totalmente e $35 \%$ concordaram parcialmente avaliando esta questão de forma positiva.

Conforme abordado sobre a categoria Trabalho e Espaço Total de Vida, podemos dizer que é uma das categorias mais importantes para garantir a qualidade de vida dos colaboradores dentro do ambiente de trabalho, já que se trata do equilíbrio entre a vida pessoal e profissional.

\subsubsection{Categoria 8- Relevância Social da Vida no Trabalho}

A relevância social da vida no trabalho tem como objetivo medir a qualidade de vida no trabalho através da percepção do colaborador em relação a responsabilidade social da organização.

Quadro 10 - Respostas Obtidas sobre Relevância Social da Vida no Trabalho

\begin{tabular}{|c|c|c|c|c|c|}
\hline \multicolumn{6}{|c|}{27 - A cooperativa valoriza e reconhece seu trabalho? } \\
\hline \begin{tabular}{c|c|} 
Não \\
Respondeu
\end{tabular} & \begin{tabular}{|c|} 
Discordo \\
Totalmente
\end{tabular} & $\begin{array}{c}\text { Discordo } \\
\text { Parcialmente }\end{array}$ & $\begin{array}{c}\text { Não } \\
\text { Concorda }\end{array}$ & $\begin{array}{c}\text { Concordo } \\
\text { Parcialmente }\end{array}$ & $\begin{array}{l}\text { Concordo } \\
\text { Totalmente }\end{array}$ \\
\hline $\mathbf{2 \%}$ & $\mathbf{8 \%}$ & $4 \%$ & $13 \%$ & $50 \%$ & $23 \%$ \\
\hline \multicolumn{6}{|c|}{28 - Os produtos e serviços que a cooperativa disponibiliza a seus clientes, você considera de qualidade? } \\
\hline $4 \%$ & $\mathbf{0} \%$ & $\mathbf{o} \%$ & $\mathbf{0 \%}$ & $19 \%$ & $77 \%$ \\
\hline \multicolumn{6}{|c|}{$\begin{array}{c}29 \text { - Você sente satisfação e orgulho em trabalhar na cooperativa e recomendaria a mesma para outras } \\
\text { pessoas? }\end{array}$} \\
\hline $4 \%$ & $\mathbf{0} \%$ & $\mathbf{2} \%$ & $4 \%$ & $30 \%$ & $60 \%$ \\
\hline \multicolumn{6}{|c|}{30 - Você percebe que a visão que a comunidade tem sobre a cooperativa é positiva? } \\
\hline $4 \%$ & o\% & $\mathbf{o} \%$ & $4 \%$ & $29 \%$ & $63 \%$ \\
\hline
\end{tabular}

Fonte: Dados da Pesquisa

Abordando a importância que o colaborador tem para a organização, foi perguntado aos colaboradores se a cooperativa valoriza e reconhece seu trabalho, os resultados foram avaliados positivamente, pois $50 \%$ concordaram parcialmente, $23 \%$ concordaram totalmente, totalizando $73 \%$ dos entrevistados satisfeitos com a situação.

A questão 28 trata-se da responsabilidade social pelos serviços e produtos oferecidos a comunidade onde está inserida, ao perguntar aos colaboradores se os produtos e serviços que a cooperativa disponibiliza a seus clientes, se os mesmos consideram de qualidade, foi constatado que a maioria dos entrevistados concordou totalmente com a questão totalizando $77 \%, 19 \%$ dos demais concordaram parcialmente e $4 \%$ não responderam. Pode-se analisar que a organização se preocupa em oferecer produtos e serviços de qualidade a seus cooperados e é visível por seus colaboradores.

Conforme a questão 29 traz os sentimentos que os colaboradores sentem em trabalhar na cooperativa Camnpal, foi perguntado aos entrevistados se sentem satisfação e orgulho em trabalhar na cooperativa e se recomendaria a mesma para outras pessoas, $60 \%$ concordaram totalmente e $30 \%$ concordaram parcialmente, obtendo um resultado satisfatório.

A última questão trata de como a responsabilidade social da organização com a comunidade é percebida por seus colaboradores, ao perguntar se você percebe que a visão que a comunidade tem sobre a cooperativa é positiva, $63 \%$ responderam que concordam totalmente, $29 \%$ concordaram parcialmente. Chiavenato (2014, p.490) diz que "a organização deve ter uma imagem perante a sociedade, responsabilidade social, responsabilidade pelos seus produtos e serviços oferecidos, deverá ter regras bem definidas de funcionamento e de administração eficiente". 
Esta categoria obteve-se resultados satisfatórios apresentado no gráfico acima, visto que independente das dificuldades apresentadas e a necessidade de melhorias, os colaboradores se sentem satisfeitos em fazer parte da equipe e orgulhosos em trabalhar em uma organização onde oferece produtos e serviços de qualidade a seus clientes.

\section{Conclusões}

A cooperativa Camnpal não apresenta formalmente programas ou benefícios diretamente voltados para a qualidade de vida no trabalho, entretanto a organização possui algumas ações que atendem aos aspectos referentes à qualidade de vida no trabalho, estas vistas na aplicação do modelo de Walton (1973), onde as características das categorias estão presentes no ambiente da pesquisa.

Ao analisar todas as categorias do modelo de Walton (1973), com base na avaliação dos colaboradores da cooperativa Camnpal, conclui-se que as categorias que apresentaram resultados satisfatórios, foram em relação à relevância social da vida no trabalho, constitucionalismo, oportunidades de crescimento e segurança, uso e desenvolvimento das capacidades e as condições de trabalho.

Em se tratando da relevância social da vida no trabalho foi visto como um dos melhores resultados situou-se uma média de $55,75 \%$ dos entrevistados que concordaram totalmente com as perguntas realizadas, ou seja, os colaboradores se sentem satisfeitos e orgulhosos em fazer parte da cooperativa e trabalhar na organização onde oferece produto de qualidade e uma ótima imagem a comunidade.

Outra categoria que obteve um nível de satisfação maior foi em relação ao uso e desenvolvimento das capacidades, onde $45,5 \%$ concordaram totalmente e 39,25\% parcialmente, visto que os colaboradores prezam por seus cargos e de certa forma possui autonomia sobre ele, contribuindo para a autoestima dos mesmos.

Ao observar as condições de trabalho, percebe-se que existe um elevado nível de satisfação, mas embora os resultados fossem positivos, necessita uma atenção maior por parte da cooperativa nas atividades que possam interferir na saúde física e mental de seus colaboradores.

Nas demais categorias citadas como uma avaliação positiva por parte dos colaboradores percebe-se que a cooperativa busca honrar com suas obrigações legais e respeita os direitos dos trabalhadores, pode-se concluir também que as oportunidades de crescimento na organização são 
interfira diretamente na vida pessoal e no tempo de lazer de seus colaboradores, seria adequado buscar estratégias que visam oferecer mais tempo livre aos mesmos sem interferir na rotina e um espaço de lazer dentro da organização.

As questões relacionada à compensação justa e adequada também merece uma atenção maior, sugerindo esclarecimento de dúvidas sobre a política salarial e oferecendo incentivos individuais e coletivos. Em relação à integração social na organização, conclui-se que os colaboradores acreditam que as oportunidades não são iguais para todos, acarretando dificuldades no clima organizacional da cooperativa e na relação com os colegas.

Verifica-se que o estudo foi viável e alcançou o objetivo proposto para o progresso da pesquisa, ressaltando que o modelo de Walton (1973) foi importante para medir o grau de satisfação sobre a qualidade de vida dos colaboradores da cooperativa Camnpal.

\section{Referências}

ALVES, E. F. Programas e ações em qualidade de vida no trabalho. Revista Interfaces EHS, v. 6, n.1, 2011.

BÚRIGO, C. C. D. Qualidade de Vida no Trabalho: dilemas e perspectivas. 1. ed. Florianópolis: Insular. 1997.

CHIAVENATO, A. Gestão de pessoas: o novo papel dos recursos humanos nas organizações. 4. ed. Barueri: Manole, 2014.

COOPERATIVA AGRÍCOLA MISTA NOVA PALMA-CAMNPAL. A empresa. Santa Maria, 2018. Disponível em: www.camnpal.com.br/CamEmp.html. Acesso em: 30 out. 2018.

FERNANDES, E. C. Qualidade de Vida no Trabalho. 1. ed. Salvador: Ed. Casa da qualidade. 1996.

FERREIRA, P. I. Clima organizacional e qualidade de vida no trabalho. Rio de Janeiro: LTC, 2014.

FERREIRA, M. C. Qualidade de vida no trabalho: uma abordagem centrada no olhar dos trabalhadores. Brasília: Editora LPA, 2011.

FRANÇA, A. C. L. Qualidade de vida no trabalho: conceitos e práticas nas empresas da sociedade pós-industrial. 2. ed. São Paulo: atlas, 2004.

GIL, A. C. Como Elaborar Projetos de Pesquisa. 5. ed. São Paulo: Atlas, 2012.

KOPS, L. M.; COSTA S. F.; ROMERO S. M. Gestão de pessoas: conceitos e estratégias. Curitiba, 2013.

LIOBA. J. Qualidade de vida no trabalho segundo modelo de Walton (1973). 2014.

MARCONI, M. A; LAKATOS, E. M. Fundamentos de metodologia científica. 7. ed. São Paulo: Atlas, 2010.

ROBBINS, S. P; JUDGE, T. A; SOBRAL, F. Comportamento organizacional: teoria e prática no contexto brasileiro. 14. ed. São Paulo: Pearson, 2010.

RODRIGUES, R. M. Pesquisa acadêmica: como facilitar o processo de preparação de suas etapas. São Paulo: Atlas, 2007. 
SCHERMERHORN, J. R; HUNT, J. G; OSBORN, R. N. Fundamentos de comportamento organizacional. 2. ed. Porto Alegre: Bookman, 2007.

SOUZA, A. O. et al. Qualidade de vida no trabalho em uma cooperativa de reciclados, Revista de Carreira e Pessoas, v. 9, n. 3, 2019.

VIEIRA, A. A Qualidade de Vida no Trabalho e o Controle da Qualidade Total. 1.ed. Florianópolis: Insular, 1996.

WALTON, R. E. Quality of working life : what is it? Sloan Management, v. 15, n. 1, p. 11-21, 1973. 